importance is the presence of $\mathrm{PO}_{4}^{3-}$ ions in the outermost layers of the oxide which inhibits any hydration of the oxide. Indeed, the oxide surface produced by the chromic-acid etch treatment may have its hydration resistance greatly increased, if phosphonic-acid based inhibitors are adsorbed onto the oxide prior to adhesive bonding. This significantly increases the durability of the subsequent adhesive joint [15].

\subsection{Kinetics of Environmental Attack}

Kinloch and coworkers [16] have undertaken quantitative predictions for the durability of unstressed butt (tensile) joints consisting of mild-steel substrates loaded with a simple epoxy adhesive. Firstly, from diffusion data for the adhesive, concentration profiles for water ingressing into the adhesive joint were calculated as a function of time and temperature. For this joint, environmental attack occurs by truly interfacial failure, as discussed above, and the kinetics of failure are governed solely by the rate of water diffusion. Secondly, therefore, by assigning a constant, critical water concentration for debonding, the interfacial environmental crack length as a function of time the joint spent in water at a given temperature was deduced. Thirdly, this crack length was combined into a continuum fracture mechanics model to predict the failure stress of the environmentally-aged joints. The predictions, over a wide range of times and temperatures were in excellent agreement with the experimentally-determined values.

[1] A.J. Kinloch, 'Adhesion and Adhesives', Chapman and Hall, London, 1987.

[2] A.N. Gent, A.J. Kinloch, J. Polym. Sci.1971, A2 659.

[3] E. H. Andrews, A.J. Kinloch, Proc. R. Soc., Lon don. [Ser.] A 1973, 332, 385.
[4] E. H. Andrews, A.J. Kinloch, Proc. R. Soc, London (Ser.]A 1973, 332, 401.

[5] E.H. Andrews, A.J. Kinloch, J. Polym. Sci. Symp., 1974, 46, 1.

[6] G.K.A. Kodokian, A.J. Kinloch, J. Mater. Sci. Letl. 1988, 7, 625 .

[7] G.K.A. Kodokian, A.J. Kinloch, J. Adhesion 1989, 29, 193.

[8] A. J. Kinloch, Ed., 'Durability of Structural Adhesives', Applied Sci., London, 1983.

[9] M. Gettings, F.S. Baker, A.J. Kinloch, J. Appl. Polym. Sci. 1977, 2I, 2375.

[10] A.J. Kinloch, L.S. Welch, H. E. Bishop, J. Adhe sion 1984, 16, 165

[11] R. A. Gledhill, A. J. Kinloch, J. Adhesion 1974, 6, 315.

[12] M. Gettings, A.J. Kinloch, J, Mater. Sci, 1977, 12,2511 .

[13] T. S. Sun, J. M. Chen, J. D. Venables, R. Hopping. Appl. Surf. Sci. 1978, 1, 202.

[14] R.J. Davies, A.J. Kinloch, Adhesion - 13, Ed K.W. Allen, Applied Sci., London, 1989, p.8.

[15] G. D. Davis J.S. Ahearn, L.J. Matienzo, J.D. Venables, J. Mater. Sci. 1985, 20, 975.

[16] R. A. Gledhill, A.J. Kinloch, S.J. Shaw, J. Adthe$\operatorname{sion} 1980,11,3$.

\title{
Improvement of Adhesion on Automotive Top Coats by Corona Discharge
}

\section{Kurt Jud*}

Abstract. A highly automated Corona Discharge treatment transforms a nonpolar, not bondattractive top coat surface into a polar, adhesively suitable substrate for structural bonding, i.e. for automotive windscreen fastening (Fig. 1). This cost-effective, secure purely physical procedure replaces the expensive, manual, wet pretreatment in applying solvent containing inflammable primers.

Investigations have shown an excellent adhesion of particularly polyurethane adhesives to Corona-Discharge-treated current automotive topcoats, independent of the type and amount of many top-coat additives. Adhesion experiments and the determination of surface energy have shown an insensitive resulting performance towards changing process parameters.

Scientific examinations with IR and ESCA analysis as well as electron microscopy provide valuable explanations for the efficiency of the Corona Discharge treatment.

\section{The Problem}

In the Automotive Industry many coated materials are bonded frequently and in great extent together with glass, plastics, and textiles today. Examples are: direct glazing, fastening of plastic parts, spoilers and friezes, bonding of SMC panels to the load bearing frame.

All paints and coatings contain additives, which ease the compounding or the application or even provide some finishing properties to the paint surface. The most important properties amongst those are as follows: dispersion, self leveling, antifoaming, pigment wetting, conductivity, brilliance, and dust repulsion.

These additives are non-volatile surfaceactive agents, which also migrate to the surface of the finished paint coating. Additives at the surface of electrocoats, surfacer, primer, and base coats become dis- solved in the next wet system applied and migrate to the surface of the top coats, i.e. the clear coats. Most additives are derivatives of silicone oils containing methyl and phenyl groups. They create a hydrophobic layer on the surface and reduce the surface energy to less than $30 \mathrm{mN} / \mathrm{m}$ (Table l). As a result, they have poor wettability characteristics when used with adhesives possessing higher surface tensions. In contrast to top coats, these surface-active agents contain no functional groups for powerful interaction or chemical reaction with conventional adhesives (Fig. 3).

Table I

\begin{tabular}{|c|c|c|c|}
\hline \multicolumn{4}{|l|}{ Surface Energy $[\mathrm{mN} / \mathrm{m}]$} \\
\hline Glass & \multicolumn{3}{|c|}{ Glass 73} \\
\hline & \multicolumn{2}{|r|}{ Glycerine } & 63 \\
\hline & \multicolumn{2}{|r|}{ Ethyleneglycol } & 48 \\
\hline & & 33 \\
\hline $\begin{array}{l}\text { Phosphatised Steel } \\
\text { Cathodic E-Coat } \\
\text { Polyethylene } \\
\text { Polypropylene }\end{array}$ & 28 & \multirow{2}{*}{$\begin{array}{l}\text { Butanol } \\
\text { Xylene }\end{array}$} & 23 \\
\hline & & 29 \\
\hline ethylene & 19 & \multirow{3}{*}{$\begin{array}{l}\text { Butylacetate } \\
\text { Diisobutyl- } \\
\text { ketone }\end{array}$} & 25 \\
\hline Alkyd Resin & $33-60$ & & \\
\hline Alkyd Melamine & & & 22 \\
\hline \multirow{2}{*}{$\begin{array}{l}\text { Top Coat } \\
\text { Polyvinylchloride }\end{array}$} & \multicolumn{2}{|r|}{ Solvent } & \\
\hline & \multirow{2}{*}{\multicolumn{2}{|c|}{$\begin{array}{l}39-42 \text { Naphtha } \\
32-41\end{array}$}} & $18-22$ \\
\hline \multirow{5}{*}{$\begin{array}{l}\text { Polymethacrylate } \\
\text { Epoxy Resin } \\
2 \text { pt Epoxy Adhesive } \\
2 \text { pt PUR Adhesive } \\
\text { Polyamide }\end{array}$} & $32-41$ & & \\
\hline & \multicolumn{2}{|l|}{4560} & \\
\hline & \multirow{2}{*}{\multicolumn{2}{|c|}{$\begin{array}{l}39-44 \\
44\end{array}$}} & \\
\hline & \multirow{2}{*}{\multicolumn{2}{|c|}{$\begin{array}{l}44 \\
46\end{array}$}} & \\
\hline & & & \\
\hline \multicolumn{2}{|l|}{ Polydimethylsiloxane 2} & \\
\hline \multirow{2}{*}{$\begin{array}{l}\text { Togocoll FH } 500 \\
\text { Togocoll FH } 500 \mathrm{DI}\end{array}$} & \multicolumn{3}{|l|}{33} \\
\hline & & \multicolumn{2}{|c|}{32} \\
\hline
\end{tabular}

* Correspondence : Dr. K. Jud

EMS-TOGO $A G$

CH-8590 Romanshorn 
importance is the presence of $\mathrm{PO}_{4}^{3-}$ ions in the outermost layers of the oxide which inhibits any hydration of the oxide. Indeed, the oxide surface produced by the chromic-acid etch treatment may have its hydration resistance greatly increased, if phosphonic-acid based inhibitors are adsorbed onto the oxide prior to adhesive bonding. This significantly increases the durability of the subsequent adhesive joint [15].

\subsection{Kinetics of Environmental Attack}

Kinloch and coworkers [16] have undertaken quantitative predictions for the durability of unstressed butt (tensile) joints consisting of mild-steel substrates loaded with a simple epoxy adhesive. Firstly, from diffusion data for the adhesive, concentration profiles for water ingressing into the adhesive joint were calculated as a function of time and temperature. For this joint, environmental attack occurs by truly interfacial failure, as discussed above, and the kinetics of failure are governed solely by the rate of water diffusion. Secondly, therefore, by assigning a constant, critical water concentration for debonding, the interfacial environmental crack length as a function of time the joint spent in water at a given temperature was deduced. Thirdly, this crack length was combined into a continuum fracture mechanics model to predict the failure stress of the environmentally-aged joints. The predictions, over a wide range of times and temperatures were in excellent agreement with the experimentally-determined values.

[1] A.J. Kinloch, 'Adhesion and Adhesives', Chapman and Hall, London, 1987.

[2] A.N. Gent, A.J. Kinloch, J. Polym. Sci.1971, A2 659.

[3] E. H. Andrews, A.J. Kinloch, Proc. R. Soc., Lon don. [Ser.] A 1973, 332, 385.
[4] E. H. Andrews, A.J. Kinloch, Proc. R. Soc, London (Ser.]A 1973, 332, 401.

[5] E.H. Andrews, A.J. Kinloch, J. Polym. Sci. Symp., 1974, 46, 1.

[6] G.K.A. Kodokian, A.J. Kinloch, J. Mater. Sci. Letl. 1988, 7, 625 .

[7] G.K.A. Kodokian, A.J. Kinloch, J. Adhesion 1989, 29, 193.

[8] A. J. Kinloch, Ed., 'Durability of Structural Adhesives', Applied Sci., London, 1983.

[9] M. Gettings, F.S. Baker, A.J. Kinloch, J. Appl. Polym. Sci. 1977, 2I, 2375.

[10] A.J. Kinloch, L.S. Welch, H. E. Bishop, J. Adhe sion 1984, 16, 165

[11] R. A. Gledhill, A. J. Kinloch, J. Adhesion 1974, 6, 315.

[12] M. Gettings, A.J. Kinloch, J, Mater. Sci, 1977, 12,2511 .

[13] T. S. Sun, J. M. Chen, J. D. Venables, R. Hopping. Appl. Surf. Sci. 1978, 1, 202.

[14] R.J. Davies, A.J. Kinloch, Adhesion - 13, Ed K.W. Allen, Applied Sci., London, 1989, p.8.

[15] G. D. Davis J.S. Ahearn, L.J. Matienzo, J.D. Venables, J. Mater. Sci. 1985, 20, 975.

[16] R. A. Gledhill, A.J. Kinloch, S.J. Shaw, J. Adthe$\operatorname{sion} 1980,11,3$.

\section{Improvement of Adhesion on Automotive Top Coats by Corona Discharge}

\section{Kurt Jud*}

Abstract. A highly automated Corona Discharge treatment transforms a nonpolar, not bondattractive top coat surface into a polar, adhesively suitable substrate for structural bonding, i.e. for automotive windscreen fastening (Fig. 1). This cost-effective, secure purely physical procedure replaces the expensive, manual, wet pretreatment in applying solvent containing inflammable primers.

Investigations have shown an excellent adhesion of particularly polyurethane adhesives to Corona-Discharge-treated current automotive topcoats, independent of the type and amount of many top-coat additives. Adhesion experiments and the determination of surface energy have shown an insensitive resulting performance towards changing process parameters.

Scientific examinations with IR and ESCA analysis as well as electron microscopy provide valuable explanations for the efficiency of the Corona Discharge treatment.

\section{The Problem}

In the Automotive Industry many coated materials are bonded frequently and in great extent together with glass, plastics, and textiles today. Examples are: direct glazing, fastening of plastic parts, spoilers and friezes, bonding of SMC panels to the load bearing frame.

All paints and coatings contain additives, which ease the compounding or the application or even provide some finishing properties to the paint surface. The most important properties amongst those are as follows: dispersion, self leveling, antifoaming, pigment wetting, conductivity, brilliance, and dust repulsion.

These additives are non-volatile surfaceactive agents, which also migrate to the surface of the finished paint coating. Additives at the surface of electrocoats, surfacer, primer, and base coats become dis- solved in the next wet system applied and migrate to the surface of the top coats, i.e. the clear coats. Most additives are derivatives of silicone oils containing methyl and phenyl groups. They create a hydrophobic layer on the surface and reduce the surface energy to less than $30 \mathrm{mN} / \mathrm{m}$ (Table l). As a result, they have poor wettability characteristics when used with adhesives possessing higher surface tensions. In contrast to top coats, these surface-active agents contain no functional groups for powerful interaction or chemical reaction with conventional adhesives (Fig. 3).

Table I

\begin{tabular}{|c|c|c|c|}
\hline \multicolumn{4}{|l|}{ Surface Energy $[\mathrm{mN} / \mathrm{m}]$} \\
\hline Glass & \multicolumn{3}{|c|}{ Glass 73} \\
\hline & \multicolumn{2}{|r|}{ Glycerine } & 63 \\
\hline & \multicolumn{2}{|r|}{ Ethyleneglycol } & 48 \\
\hline & & 33 \\
\hline $\begin{array}{l}\text { Phosphatised Steel } \\
\text { Cathodic E-Coat } \\
\text { Polyethylene } \\
\text { Polypropylene }\end{array}$ & 28 & \multirow{2}{*}{$\begin{array}{l}\text { Butanol } \\
\text { Xylene }\end{array}$} & 23 \\
\hline & & 29 \\
\hline ethylene & 19 & \multirow{3}{*}{$\begin{array}{l}\text { Butylacetate } \\
\text { Diisobutyl- } \\
\text { ketone }\end{array}$} & 25 \\
\hline Alkyd Resin & $33-60$ & & \\
\hline Alkyd Melamine & & & 22 \\
\hline \multirow{2}{*}{$\begin{array}{l}\text { Top Coat } \\
\text { Polyvinylchloride }\end{array}$} & \multicolumn{2}{|r|}{ Solvent } & \\
\hline & \multirow{2}{*}{\multicolumn{2}{|c|}{$\begin{array}{l}39-42 \text { Naphtha } \\
32-41\end{array}$}} & $18-22$ \\
\hline \multirow{5}{*}{$\begin{array}{l}\text { Polymethacrylate } \\
\text { Epoxy Resin } \\
2 \text { pt Epoxy Adhesive } \\
2 \text { pt PUR Adhesive } \\
\text { Polyamide }\end{array}$} & $32-41$ & & \\
\hline & \multicolumn{2}{|l|}{4560} & \\
\hline & \multirow{2}{*}{\multicolumn{2}{|c|}{$\begin{array}{l}39-44 \\
44\end{array}$}} & \\
\hline & \multirow{2}{*}{\multicolumn{2}{|c|}{$\begin{array}{l}44 \\
46\end{array}$}} & \\
\hline & & & \\
\hline \multicolumn{2}{|l|}{ Polydimethylsiloxane 2} & \\
\hline \multirow{2}{*}{$\begin{array}{l}\text { Togocoll FH } 500 \\
\text { Togocoll FH } 500 \mathrm{DI}\end{array}$} & \multicolumn{3}{|l|}{33} \\
\hline & & \multicolumn{2}{|c|}{32} \\
\hline
\end{tabular}

* Correspondence : Dr. K. Jud

EMS-TOGO $A G$

CH-8590 Romanshorn 


\section{Effect}

In many cases, as a result of poor wetting, insufficient compatibility, and lack of functional or polar groups, adhesion of the adhesive is unsatisfactory, and the bond strength is lower than specified. Additionally, in the case of trim moldings, the molding may separate itself from the paint. To cope with such problems, it is necessary to mask the adhesion zone before applying the top coat or to utilize a paint primer in the adhesion zone. Both alternatives are expensive, labor intensive, and create another error parameter in the process.

To obtain improved reliability, higher bond strengths and lower production costs for windshield and backlight assembly operations in the world-wide automotive industry, the Corona Discharge process will be introduced.

\section{Process}

The main feature of the process is the use of high-frequency corona-discharge technique, already widely used in the olefin film industry to improve bonding characteristics for adhesives and printing inks. During the process, the paint surface in the adhesive zone is exposed to corona discharge by an electrode, which is robotically controlled. The discharge creates molecular alterations in the surface of the paint (Fig. 2).

A high-frequency current is used to develop a discharge between the high-tension electrode and the painted panel surface. The gap between the electrode and the surface is ionized, producing reactive radicals and ozone. Besides oxygen and nitrogen radicals and ions, nitrogen oxides $\left(\mathrm{NO}_{\mathrm{x}}\right)$ are formed. Oxygen and $\mathrm{NO}_{\mathrm{x}}$ are deposited on the treated surface with the resultant formation of polar groups in the boundary layer molecules. Typically, carboxyl, carbonyl, hydroxyl, nitro, and ether groups are present in the treated surface. Additional impacts of accelerated electrons and

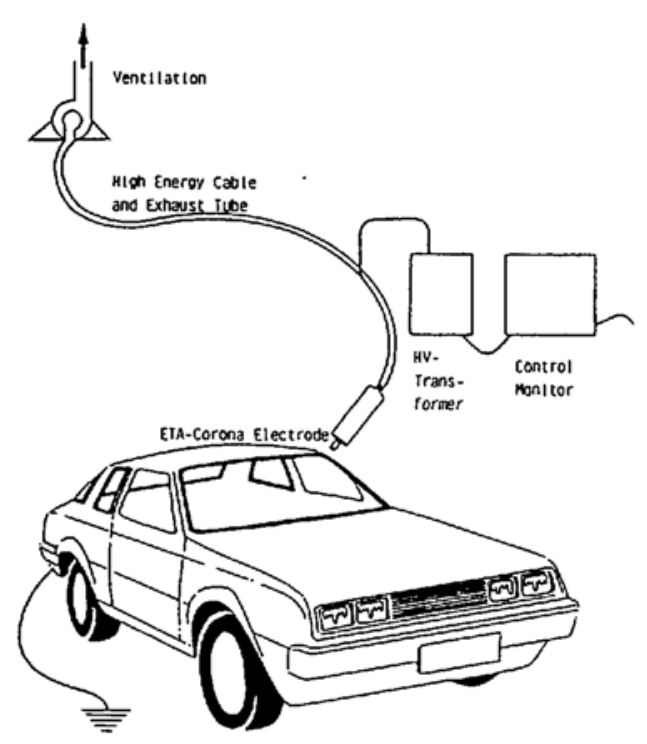

Fig. 1. Corona discharge treatment

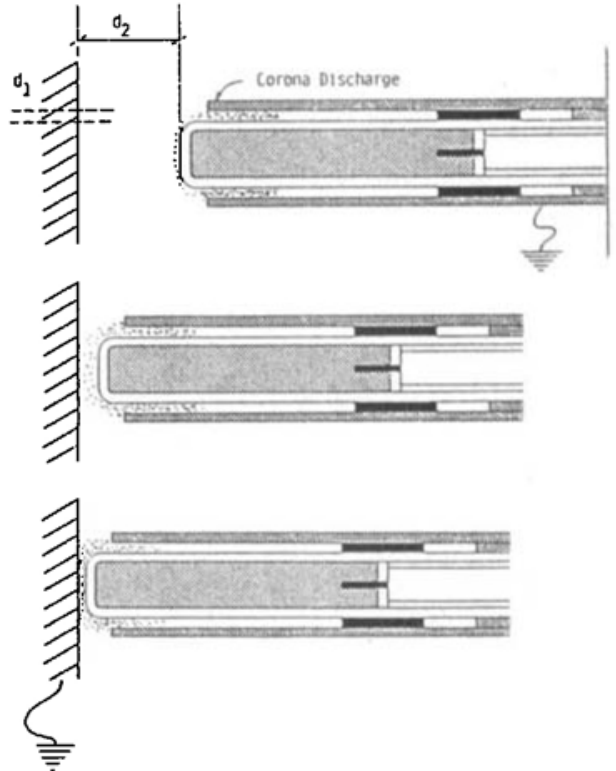

Fig. 2. Corona build-up between electrode and work piece

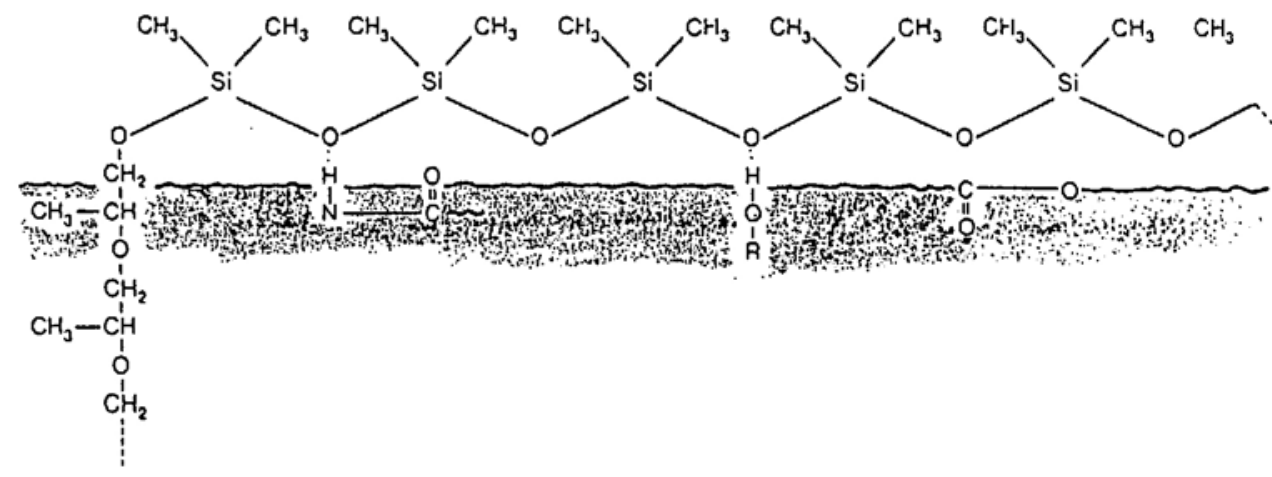

Fig. 3. Paint additive on the paint surface

ions lead to a partial cleavage of $\mathrm{C}-\mathrm{C}$ bonds and secondary reactions at the exposed surface.

Significantly higher 'wettability' and substantially improved compatibility and reactivity to adhesives is the result of the modified molecular layers in the painted surface.

The electrode has a diameter of 3 to $5 \mathrm{~cm}$ and a length of $30 \mathrm{~cm}$. Within the active area of $c a .10 \mathrm{~cm}^{2}$ corona discharge takes place. All exposed surfaces of the equipment are grounded (Fig. 2). $\mathrm{NO}_{x}$ and $\mathrm{O}_{3}$ generated by the corona discharge are evacuated through the gap between the electrode and the jacket by vacuum. Subsequently, these gases are passed through a catalyst system where they are converted to harmless products. For the corona treatment, the moving electrode is spaced

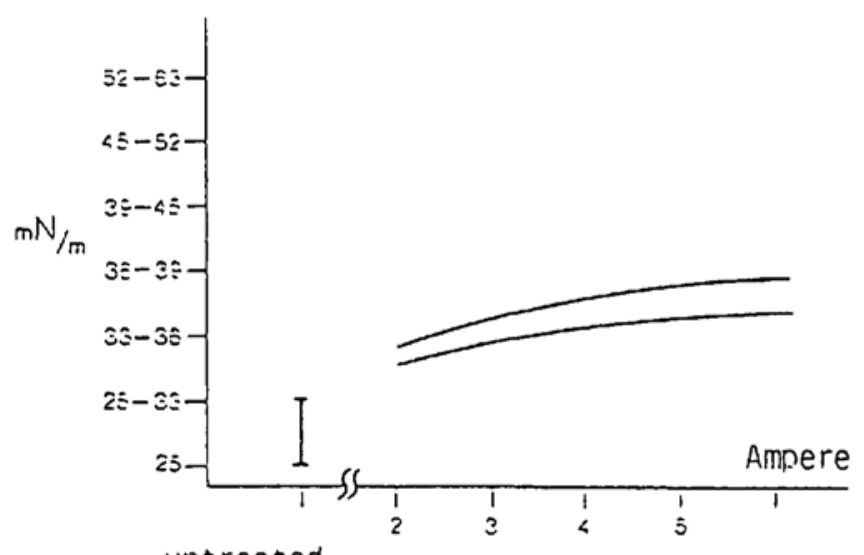

untreated

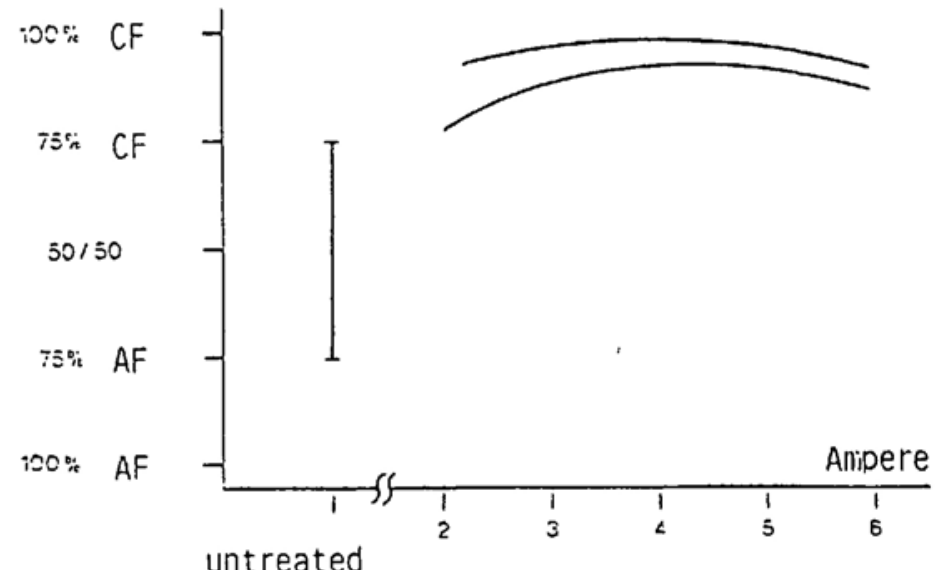

$A F=$ Adhes! ve Fallure

$C F=$ Cohesive Fallure

Fig. 4. Surface tension and peel adhesion vs. effect of current 


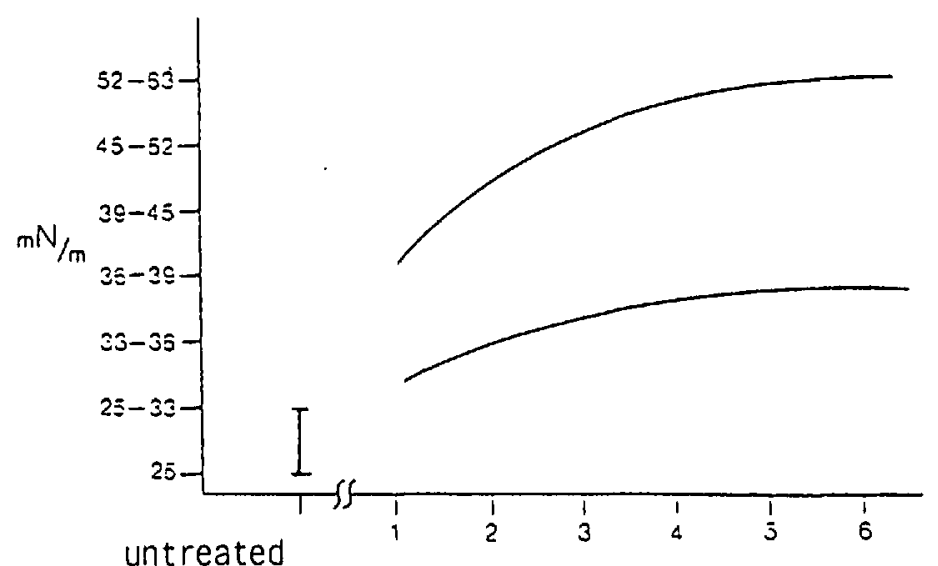

Fig. 5. Surface tension and peel adhesion vs. effect of number of treatments

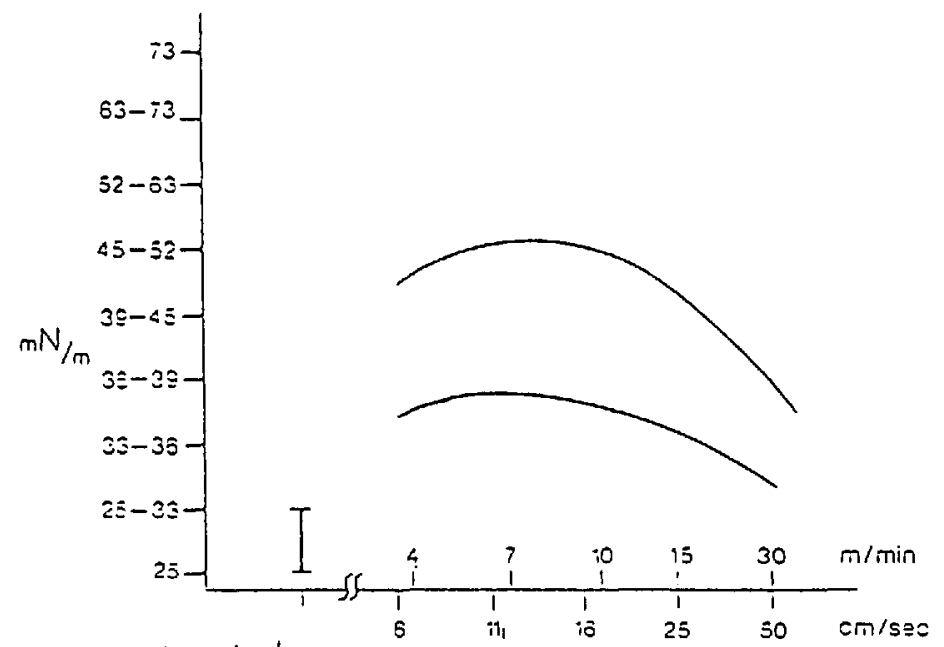

untreated

Fig. 6. Surface tension and peel adhesion vs. effect of traverse speed

equidistantly of $2-4 \mathrm{~mm}$ to the surface by a free arm robot, and the surfaces are normally treated at a linear speed of 10 to 30 $\mathrm{m} / \mathrm{min}$. With a fixed arrangement, the electrodes are positioned in a row configuration, a few millimeters from the surface, during 0.3 to $3 \mathrm{~s}$.

In contrast to corona treated plastic films, which in time, lose the molecularly changed surface structure, corona-treated painted surfaces retain the molecularly changed layer on the surface. Therefore, treated surfaces may be bonded immediately, or several days later, if contamination with dirt and oil is prevented.

\section{Equipment, Parameters, Results}

The equipment for corona-discharge treatment of paint surfaces consists of a high-voltage transformer, a generator and an electrode, whose particular property is its inherent safety, since no electrical potential is developed between the electrode and ground for an operating or unused electrode. The ionized air surrounding the surface of the electrode tip has a high con-

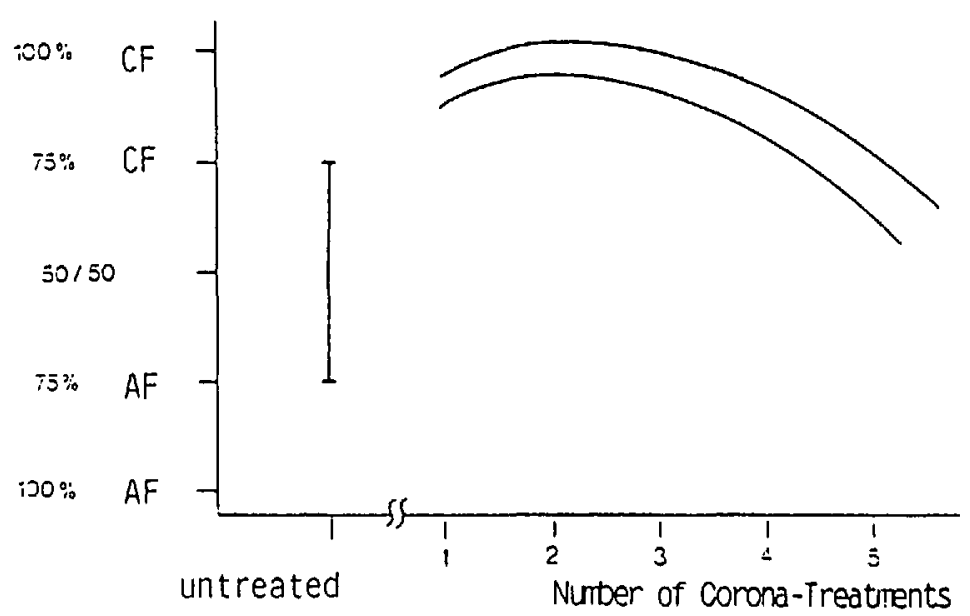

$A F=$ Adhesive Fallure

$\mathrm{CF}=$ Cohes Ive Fallure

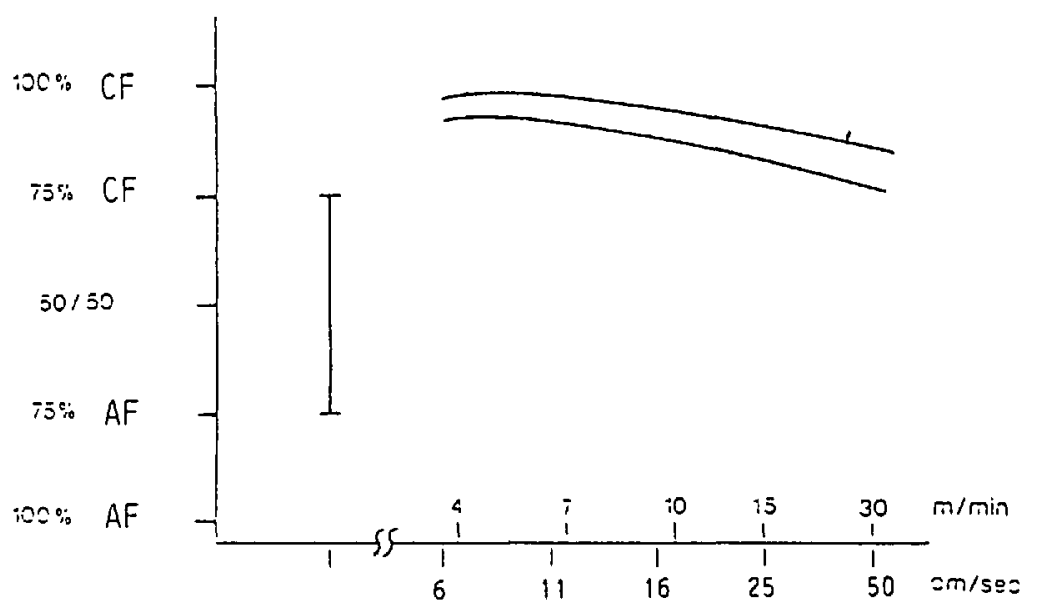

untreated

$A F=$ Adhesive Fallure

$C F=$ CohesIve Fallure
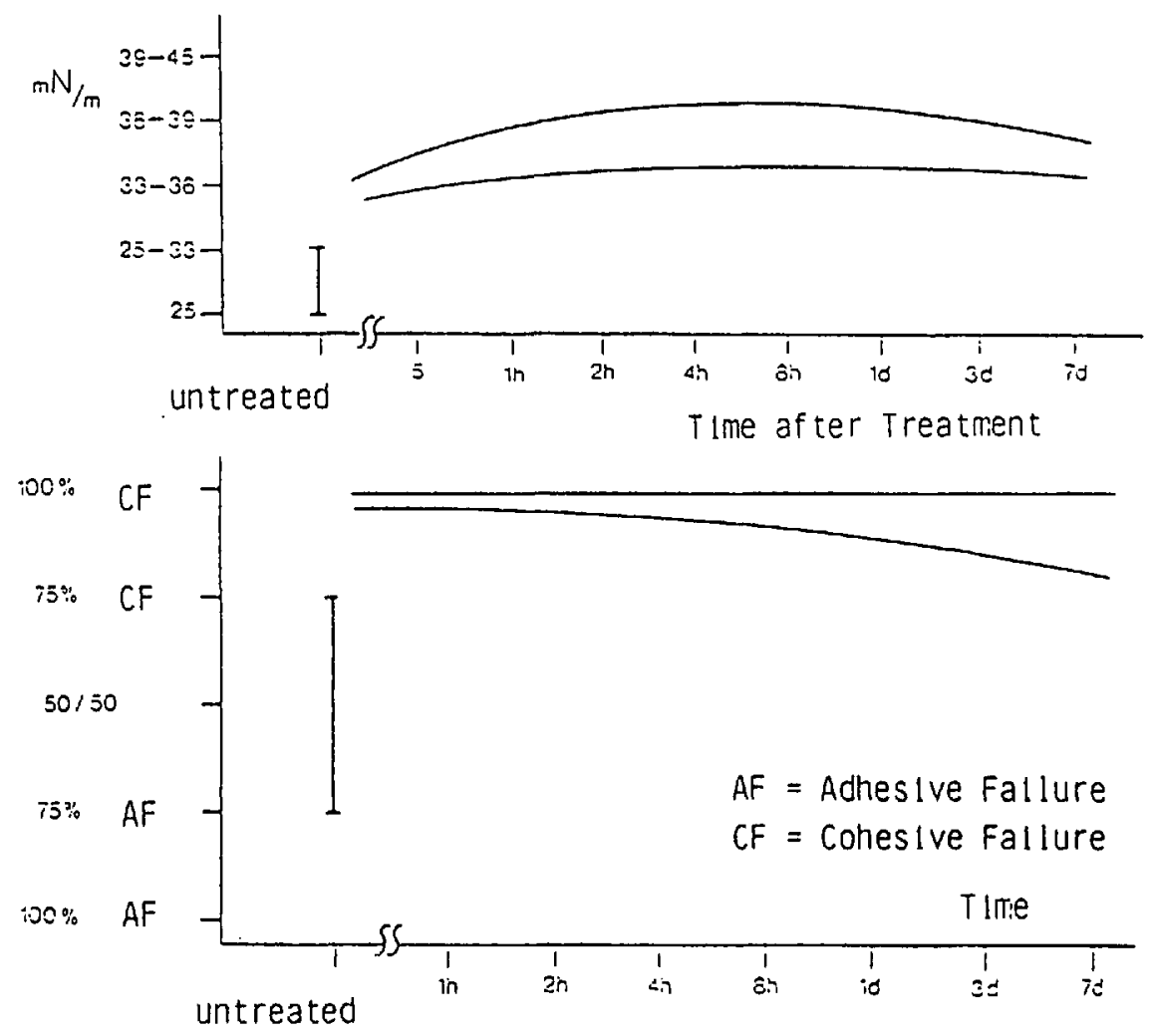

Fig. 7. Surface tension vs. time after treatment and peel adhesion vs. effect of time interval between treatment and application of adhesive 
ductivity and is in contact with the grounded jacket. Even by touching the electrode accidentally during operation, no electrical shock must be feared. Approaching a painted surface with the electrode, the corona discharge is preferentially formed between the electrode and the painted surface. In the gap between the electrode and the jacket, air may be evacuated to remove free $\mathrm{O}_{3}$ and $\mathrm{NO}_{x}$ products by ventilation or in a solid-state catalyst.

\section{Testing the Efficiency of the}

\section{Corona-Discharge Treatment}

Surface energies of the paint surfaces before and after the corona treatment have been determined to be between 22 and 70 $\mathrm{mN} / \mathrm{m}$ by using test inks of known surface energies. Adhesion properties have been measured on bonds with a direct glazing adhesive on the basis of a one-part moisture cure polyurethane. Changes taking place in the treated surface were recorded by IR analysis, ESCA (XPS) method and electronmicroscopy. The efficiency was tested on numerous European and USA serial and model top coats (Table 2). A two-component polyurethane top coat, in commercial use at a German automobile producer, was used as a base to prepare samples with varying additive formulations. Amounts, type, and composition of the used additives are listed in Table 3.

\section{Results}

The following figures illustrate the dependence of adhesion and surface tension on varied process-treatment parameters for the range of European and USA paint systems. The evaluation of the peel fracture surface of adhesive bonds suits well to judge the quality of adhesion. The adhesion ranges from $100 \%$ adhesive fracture (af , complete loss of adhesion), to 100\% cohesive fracture in the adhesive (cf). Fig. 4 illustrates that peel adhesion and surface energy is relatively unaffected by increasing current levels. Variations may occur in the generator and by variable distances of the electrode to the material surface.

Table 2. Production Top Coats

\begin{tabular}{ll}
\hline $\begin{array}{l}\text { European Manufacturers } \\
\text { Paint No. }\end{array}$ \\
\hline 16 & Daimler-Benz \\
17 & BMW \\
18 & Citroen \\
19 & Ford \\
20 & GMI \\
21 & GM II \\
22 & Opel \\
23 & Peugeot \\
24 & VW \\
\hline USA Manufacturers \\
Paint No. & \\
\hline 25 & GM 2-layer base coat/clear coat \\
26 & Ford straight shade (Inmont) \\
27 & Ford 2-layer top coat \\
28 & Nissan straight shade \\
29 & Nissan 2-layer base coat/clear coat \\
\hline
\end{tabular}

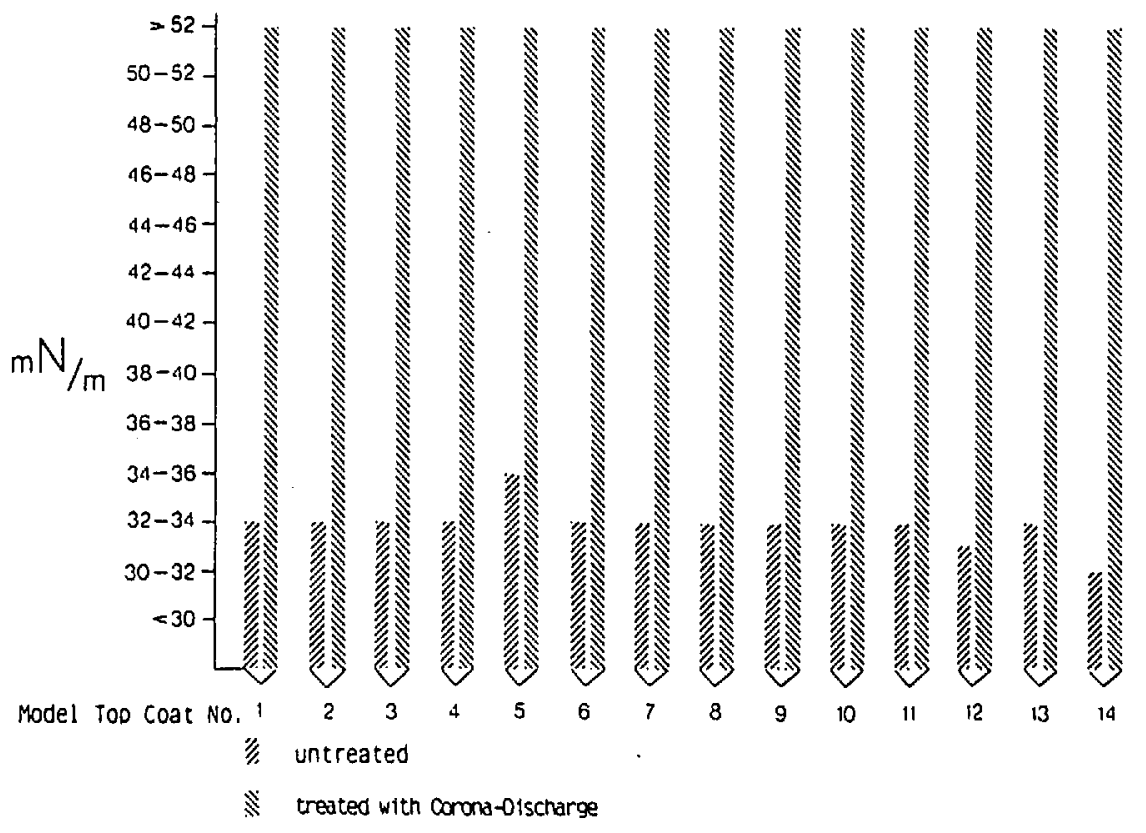

Fig. 8. Surface energy of Herberts model top coats

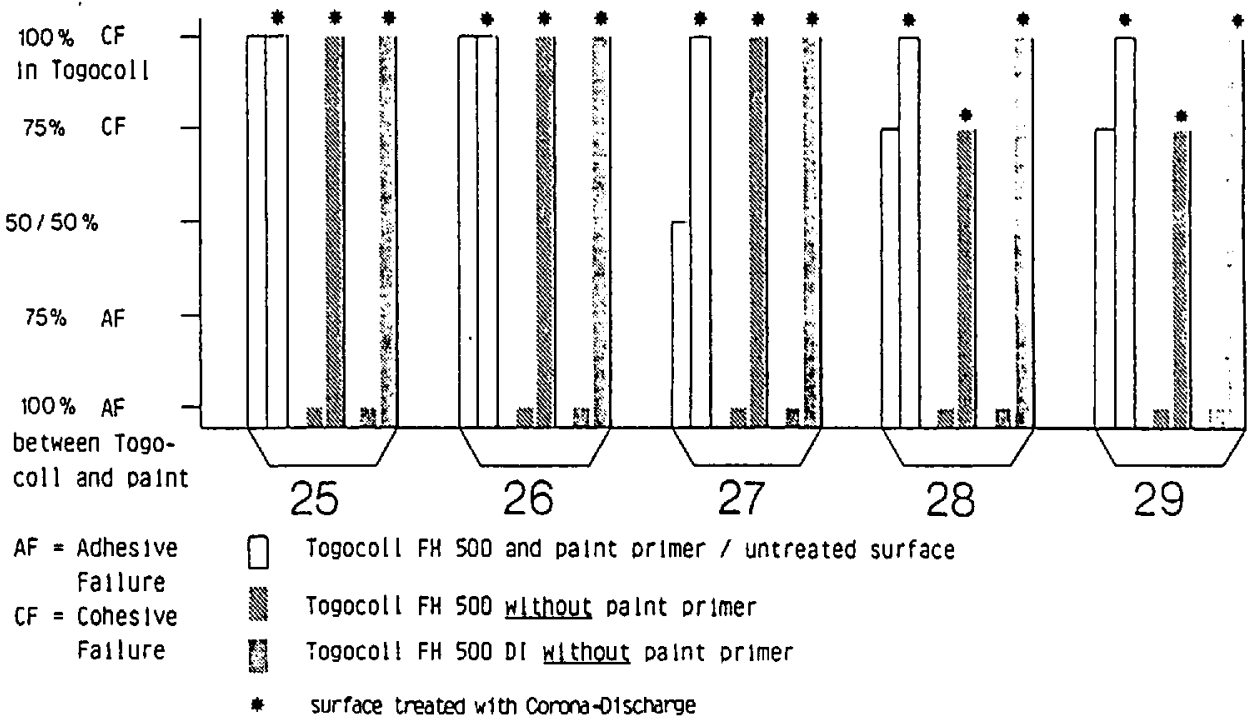

Fig. 9. Peel adhesion tests of USA top coats

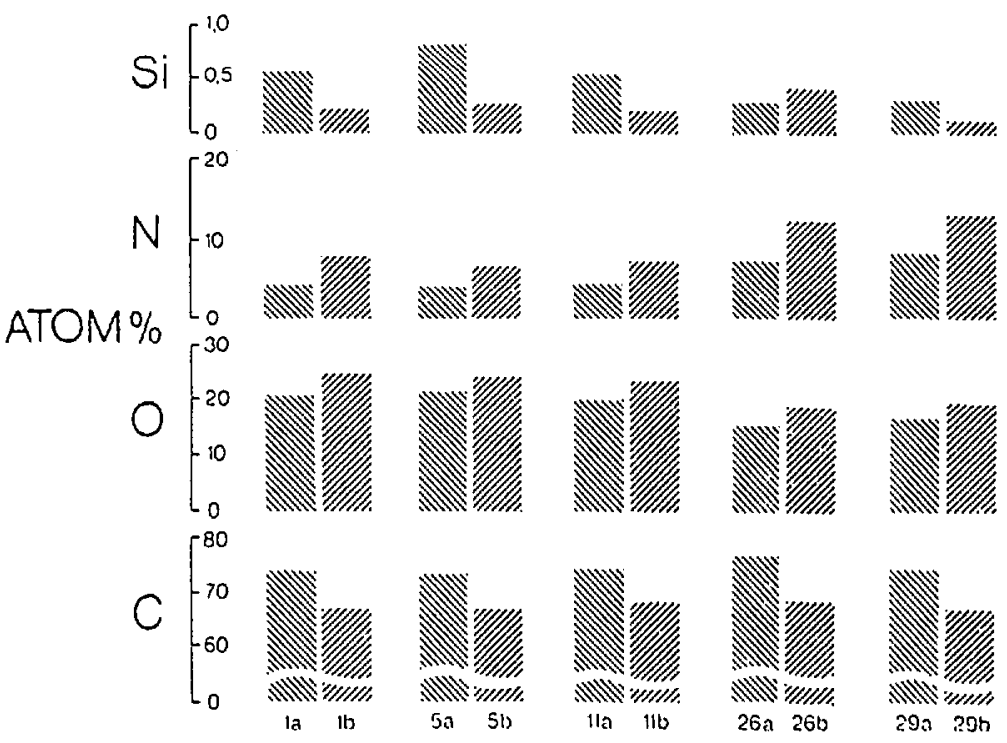

Fig. 10. Composition change of paint surfaces by corona treatment. $a$ ) Untreated, $b$ ) after treatment. 
Tablc 3. Model Top Coats for Corona Treatment

\begin{tabular}{|c|c|}
\hline Adhesion Trials & Composition \\
\hline \multicolumn{2}{|l|}{ 1. Original 2-component high solids PUR top coat } \\
\hline 2. Original $+0.2 \%$ Dimethylaminol & Diethanolamine \\
\hline 3. Original $+0.2 \%$ Byk P $104 \mathrm{~S}$ & Salt of an unsaturated polycarbonic acid \\
\hline 4. Original $+0.5 \%$ Duomeen TDO-Lsg. $15 \%$ & cationic stearylamine derivative \\
\hline 5. Original $+0.2 \%$ Byk $354 / 50$ & Clear polyacrylate \\
\hline 6. Original $+0.3 \%$ Disperbyk $160 / 30$ & $\begin{array}{l}\text { Alkanolamine salt of high molecular weight, Polyacrylic acid } \\
\text { copolymers }\end{array}$ \\
\hline 7. Original $+1.0 \%$ Silicon Oil OL $1 \%$ (Bayer) & Methylphenylpolysiloxane, polyethermodified \\
\hline 8. Original $+0.1 \%$ Silicon Oil OL $10 \%$ (Bayer) & Methylphenylpolysiloxane, polyethermodified \\
\hline 9. Original + $0.1 \%$ Silicon Oil AMRA (Langer) & Silicon oil \\
\hline 10. Original + $1.0 \%$ Silicon Oil PL (Bayer) & Low-molecular-weight methylphenylpolysiloxane \\
\hline 11. Original $+1.0 \%$ Silicon Oil $A$ & Middle molecular weight polydimethylsiloxane \\
\hline$+1.0 \%$ Tego-Glide 100 & Polyethermodified silicc \\
\hline 13. Original + $1.0 \%$ Silicon Oil MA (Bayer) & $\begin{array}{l}\text { Low-molecular-weight polydimethylsiloxane with highly } \\
\text { volatile portion }\end{array}$ \\
\hline 14. Original + $0.1 \%$ Silicon Oil L7500 & Silicon oil with polyether side chains \\
\hline & ylsiloxane \\
\hline
\end{tabular}

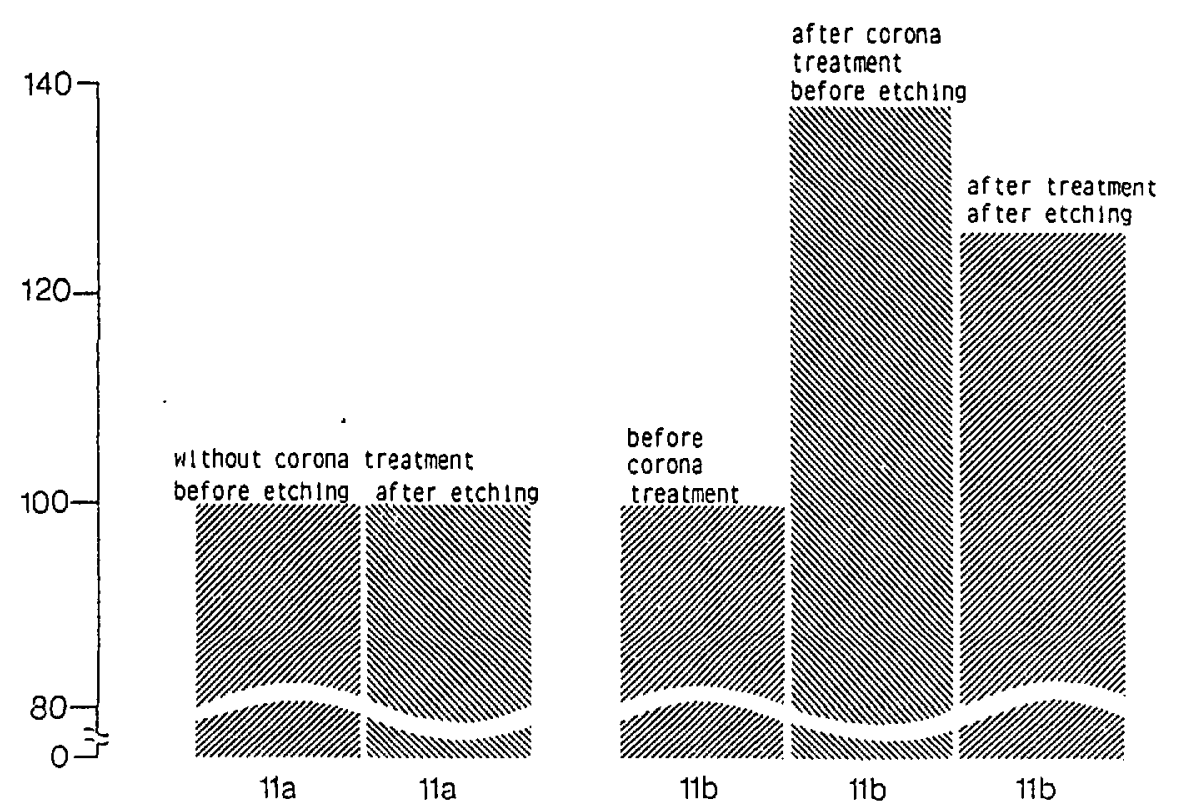

Fig. 11. Relative nitrogen content of the surface before/after Ar ion etching

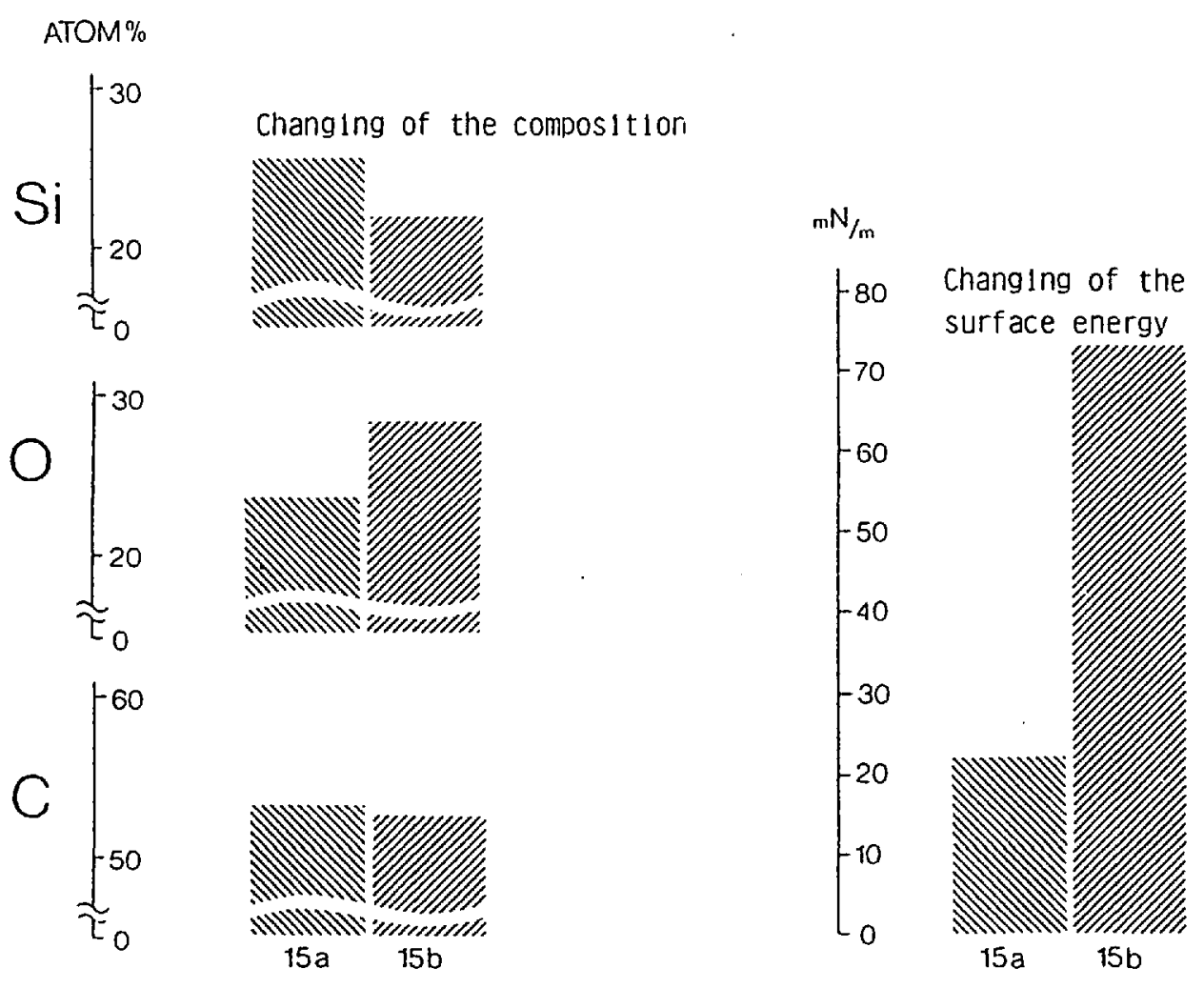

Fig. 12. The effect of corona treatment of the surface of polydimethylsiloxane
Fig. 5 illustrates that two or three-fold treatment, i.e. in repair, is barely altering the positive result. However, after multiple applications or long-lasting treatment, peel adhesion may impair as a result of damage to the surface molecules due to further bond scission or oxidative degradation from continued application of the corona treatment. The surface tension is monotonically increasing with the number of treatment, demonstrating that the improvement in wetting is not necessarily parallel to the peel adhesion, since a treated, weak boundary layer may still increase its wetting properties, while a strength decrease occurs. Fig. 6 shows that with a constant level of current, the speed can be varied between 3 and $30 \mathrm{~m} / \mathrm{min}$ without affecting the strength performance, since the minimum requirement of surface energy for good wetting is always fulfilled.

Contrary to the corona treatment of polyolefins, the increase in adhesion is not dependent on the time interval between the corona treatment and the application of the adhesive or assembly of the treated parts. It must, however, be ensured that there is no contamination of the treated surface between treatment and bonding. Fig. 7 shows that, even after an interval of $7 \mathrm{~d}$, there is practically no loss of the adhesive effect.

The exceptional effectiveness of the corona treatment and independence of the composition of the paint system is illustrated in Fig. 8, which shows that the surface tension of the paint samples increases critical levels of about $30 \mathrm{mN} / \mathrm{m}$ before treatment to over $50 \mathrm{mN} / \mathrm{m}$ after the treatment, independent of the quantity and kind of additive. Such surfaces can also be perfectly wetted with very polar bonding agents, even with aqueous systems. Although the adhesion to the model top coats is sufficient with polyurethane adhesives without pretreatment, the potential of this method may be clearly demonstrated.

The resuits of improved adhesion achieved by the corona process on 5 USA high-solid top coats are quoted as representative for a large number of serial topcoats in Fig. 9. The left and right columns of each pair of columns describe the results before and after being treated with the corona process. The left-hand pair of columns illustrates the adhesion of the TOGOCOLL FH 500 direct glazing adhesive in general use combined with the use of a priming agent, the middle pair of columns shows the primerless adhesion the same material before and after being treated and the right-hand pair of columns illustrates the adhesion of a new generation direct glazing adhesive containing additional adhesion additives (TOGOCOLL FH $500 \mathrm{DI}$ ).

Although neither of the two adhesives show sufficient adhesion to these top coats without priming before treatment, adhesion values higher than those required by industry are received after the corona 


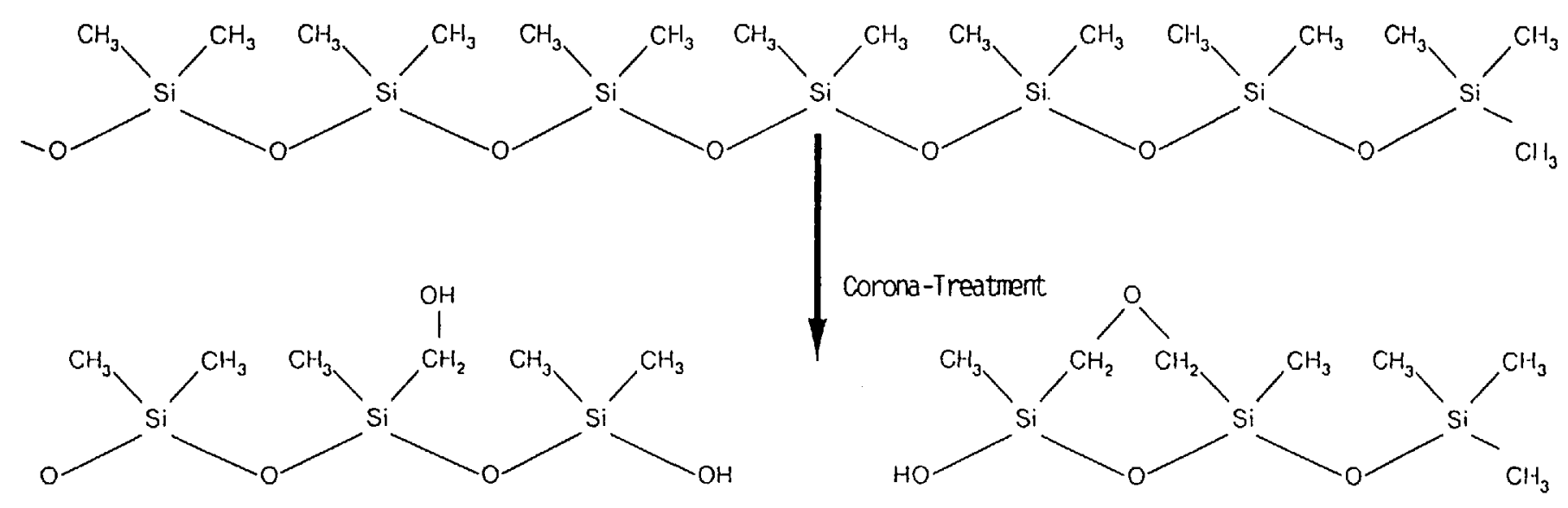

Fig. 13. Effect of the corona treatment on the structure of polydimethylsiloxane

treatment. The fact that, on certain untreated high-solid top coats, perfect adhesion cannot even be achieved, when using primers, is also very illustrative. This problem led to certain American manufacturers covering the bonding areas of the window flanges with masking tape after the application of the electrocoat and later bonding to electrocoat layers which do not have the adhesive problems of high-solid top coats.

\section{Explanations}

Our examinations of the paint surfaces before and after the ETA treatment by means of IR spectrometry, electron microscopy, and ESCA-analysis have shown chemical changes in a few molecular surface layers of the top coat to be responsible for the adhesive effect. As expected, the oxygen content of the layers increased through the corona treatment, but the even bigger increase in nitrogen due to surface nitration by formation of nitric oxides was unexpected and astonishing. In Fig. 10 the changing amounts of silicon, nitrogen, oxygen, and carbon before and after the corona treatment are displayed. The oxygen increase due to the corona treatment is between 10 and $20 \%$, whereas the nitrogen content increases by 40 to $100 \%$ depending on the paint system. To get a better picture an Ar ion etching on the corona treated surface has been carried out (Fig. 11 ). This etching process is able to level off the very top nanometers of the surface and thus may reveal the order of the nitrated layers. By the Ar etch in this case, an approximate layer of 20 nanometers was carried away. Therefore we can estimate the modified surface layer thickness to be of the order of 50-60 nanomters.

It is also remarkable to note that, through the corona treatment, silicon additives on the surface are partly changed to adhesion-compatible oxidised products and partly degraded to volatile fragments.
In Fig. 12, the effect of corona treatment on the surface of polydimethylsiloxane is illustrated by the changing amount of silicon, oxygen, and carbon in the very top surface layers measured by IR spectroscopy. The change of the molecular structure of the polydimethylsiloxane into hydroxymethyl-, hydroxy- and ethergroup-containing siloxanes was determined by ESCA analysis and illustrated in Fig. 13.

\section{Summary}

Through the corona treatment, adhesion resistant top coats become adhesioncompatible substrates for polyurethane adhesives. This reliable, purely physical process which can be automated, replaces the expensive, manual, wet pretreatment using body primers containing solvents which are inflammable.

\section{Recent Developments in the Field of Powder Coatings}

\section{Jean-Marie Loutz*}

\section{Introduction}

In 1960, the first electrostatic spray experiments were carried out allowing the application of powder paint to cold and intricately shaped metallic objects. With this process, it is possible to apply films, with a thickness varying from 40 to 300 $\mu \mathrm{m}$, in one single coat. At that date powders based on epoxy resins and dicyandiamide hardener were used in the functional coating field, e.g. for pipe protection. Due to photodegradation of bisphenol A based epoxies, leading to chalking and loss of gloss, there was a need to develop alternative mixtures of resins and cross-linkers for the decorative coating market.

Following the emergence of several possibilities to overcome the drawback, associated with bad weatherability, various directions were taken on the different continents. The USA and Canada chose the so- called polyurethane powders (in fact the urethane is made in situ from blocked isocyanate and hydroxylated polyester), because the dominant position of the automotive industry for which the flow of the paint is of prime importance. Japan opted for acrylic copolymers, recognized for their resistance to UV-induced degradation. containing glycidyl methacrylate which are cross-linked by means of long chain aliphatic diacids. Trials conducted with these systems failed in Europe either due to the volatile emission of caprolactam during baking or to poor mechanical proper-

\footnotetext{
* Correspondence: Dr. J.-M. Loutz $U C B$
}

Speciality Chemicals Division

B-1620 Drogenbos 